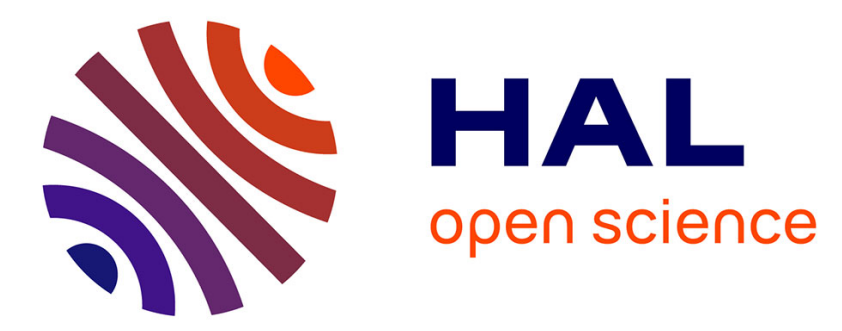

\title{
Strain Balanced Quantum Well Monolithic Tandem Solar Cells
}

\author{
A. Ioannides, T.N.D. Tibbits, J.P. Connolly, D.B. Bushnell, K.W.J. Barnham, \\ C. Calder, G. Hill, J.S. Roberts, G. Smekens
}

\section{To cite this version:}

A. Ioannides, T.N.D. Tibbits, J.P. Connolly, D.B. Bushnell, K.W.J. Barnham, et al.. Strain Balanced Quantum Well Monolithic Tandem Solar Cells. 2006 IEEE 4th World Conference on Photovoltaic Energy Conference, May 2006, Waikoloa, United States. pp.753-756, 10.1109/WCPEC.2006.279565. hal-02642932

\section{HAL Id: hal-02642932 \\ https://hal.science/hal-02642932}

Submitted on 20 Sep 2020

HAL is a multi-disciplinary open access archive for the deposit and dissemination of scientific research documents, whether they are published or not. The documents may come from teaching and research institutions in France or abroad, or from public or private research centers.
L'archive ouverte pluridisciplinaire HAL, est destinée au dépôt et à la diffusion de documents scientifiques de niveau recherche, publiés ou non, émanant des établissements d'enseignement et de recherche français ou étrangers, des laboratoires publics ou privés. 


\title{
Strain Balanced Quantum Well Monolithic Tandem Solar Cells
}

\author{
A. loannides ${ }^{1}$, T.N.D. Tibbits ${ }^{1}$, J.P. Connolly ${ }^{2}$, D.B. Bushnell ${ }^{3}$, K.W.J. Barnham ${ }^{1}$, C.Calder ${ }^{4}$, G.Hill ${ }^{4}$, J.S. Roberts ${ }^{4}$, \\ G. Smekens ${ }^{5}$
}

${ }^{1}$ Experimental Solid State Physics, Blackett Laboratory, Imperial College London, SW7 2BW, UK

${ }^{2}$ LECA (UMR 7575 CNRS), Ecole Nationale Supérieure de Chimie de Paris, 75005, Paris

${ }^{3}$ International Rectifier Co. (GB) Ltd, Fairview Industrial Estate, Hurst Green, Oxted, Surrey, RH8 9BB, UK

${ }^{4}$ EPSRC National Centre for III-V Technologies, University of Sheffield, Sheffield, S1 3JD, U.K

${ }^{5}$ Energies Nouvelles et Environnement, B-1150 Brussels, Belgium

\begin{abstract}
The effect of incorporating strain balanced multiquantum well structures in InGaP/GaAs monolithic tandem solar cells is investigated. At present the majority of InGaP/GaAs tandem cells are current limited by the bottom GaAs junction. Incorporation of multi-quantum well structures in the GaAs bottom junction extends the cell absorption to longer wavelengths. This allows current matched dual junction tandem cells to achieve higher efficiencies. InGaP/GaAs tandem cells have been studied by overgrowing different top cells on two similar quantum well structures and compared to a InGaP/GaAs control cell. A current matched top cell is presented and efficiency enhancement of a tandem by a quantum well cell demonstrated experimentally for the first time.
\end{abstract}

\section{INTRODUCTION}

The best InGaP/GaAs monolithic tandem solar cell today has an AM1.5g efficiency of $30.2 \%$ [1]. However, as with most InGaP/GaAs tandem solar cells, it is current limited by the bottom GaAs junction [2]. Incorporating strain balanced multi-quantum well solar cell (SB-QWSC) structures in GaAs cells has been shown to extend the absorption of the cell to the longer wavelengths [3]. The increase in photocurrent due to the SB-QWSC structure over-compensates the drop in open circuit voltage thus enhancing the efficiency compared to a bulk GaAs cell [4]. Modelling shows that the ability of the SB-QWSC to optimize the band-gap of the current-limiting GaAs cell in a In GaP/GaAs tandem without influencing the band-gap of the InGaP top cell can significantly enhance tandem efficiencies [5].

Currently there are no ternary alloys with lower bandgap that are lattice matched to GaAs or Ge (see Fig. 1). The SB-QWSC is lattice matched to GaAs and we have also successfully grown them on $\mathrm{Ge}$ substrates. InGaP/InGaAs tandem cells have achieved efficiencies above $30 \%$ on relaxed or virtual substrates [1] but there is always a residual dislocation density which is completely absent in the SB-QWSC [3]. Furthermore, as can be seen from Fig. 1, as the InGaAs band-gap reduces with increasing lattice constant under relaxation, the band-gap of the InGaP top-cell also reduces.

The use of strained InGaAs quantum wells has been suggested for enhancing tandems [6] but we have shown that it is not possible to grow sufficient strained wells before relaxation occurs, dramatically reducing the voltage performance [3]. Other possible materials, such as GalnNAs dilute nitrides, have not yet achieved the required photocurrent densities to be considered suitable candidates [7].

In this paper results are presented for $\ln \mathrm{GaP} / \mathrm{GaAs}$ dual junction monolithic solar cells featuring a SB-QWSC in the GaAs junction which show efficiency enhancement in a tandem SB-QWSC for the first time.

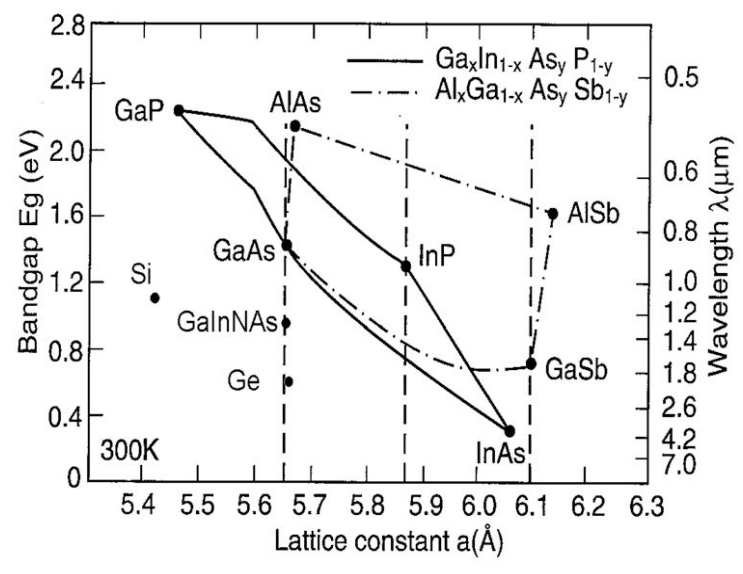

Fig. 1. Band-gap energy variation with lattice constant for GalnAsP and AlGaAsSb alloys [8]. 


\section{SB-QWSC TANDEMS}

A contour plot of AM1.5d tandem cell efficiencies as a function of top and bottom cell band-gaps at $300 x$ concentration is shown in Fig. 2 [5]. The band-gap of the InGaP/GaAs tandem corresponds to the intersection of the two lines. Lowering the band-gap of the GaAs cell without changing the InGaP band-gap, as with a SB-QWSC, moves the intersection along the horizontal line directly to the $38 \%$ contour. In an InGaP/InGaAs tandem cell, grown on a relaxed substrate, the movement is diagonal, parallel to the contours in this region. In addition the GaAs cell band-gap reduction by means of a SB-QWSC is achieved without introducing any misfit dislocations [3]. Fig. 3 depicts the band structure diagram of a SB-QWSC.

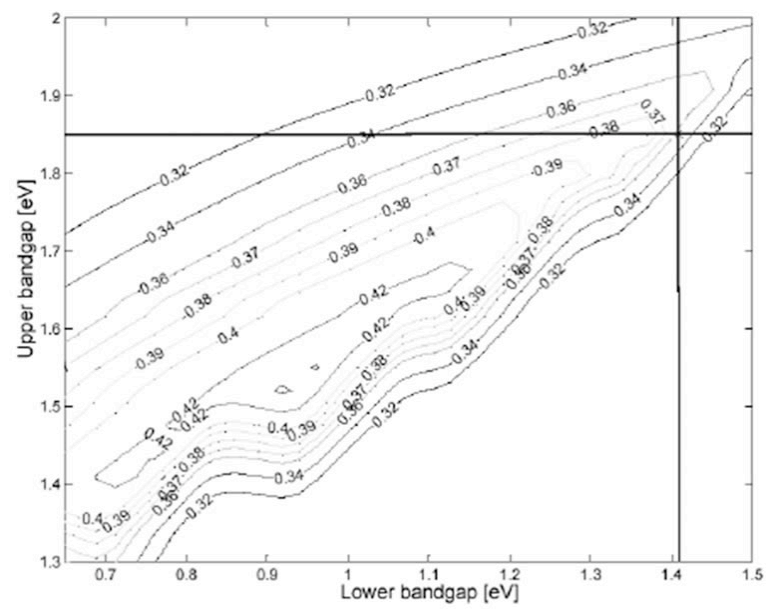

Fig. 2. Optimum bandgap combinations contour plot for AM1.5d spectrum (300x concentration). Intersecting lines depict the $\operatorname{lnGaP} / \mathrm{GaAs}$ tandem cell [5].

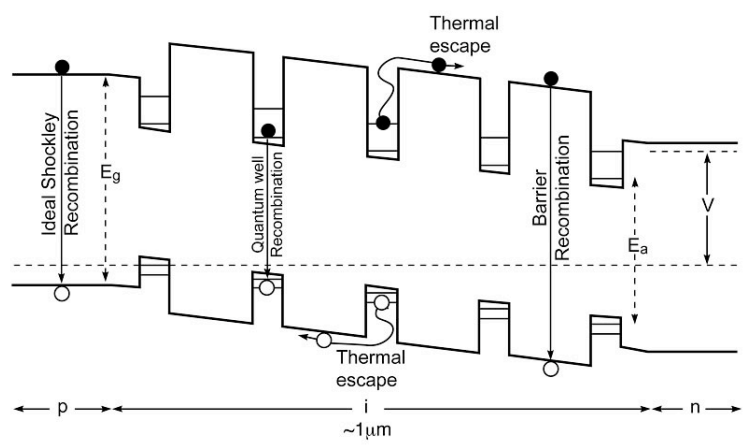

Fig. 3. Band structure diagram of a SB-QWSC.

The strain balancing technique seeks to balance the compressive stress developed by the InGaAs wells. This is achieved with the insertion of GaAsP barriers on either side of each InGaAs well. By appropriate choice of layer compositions and widths, the smaller lattice constant GaAsP barriers provide tensile stress. On average the barrier-well-barrier structure has zero residual stress in the bulk GaAs cell (see Fig. 4). This technique produces no misfit dislocations even for large numbers of quantum wells [3].

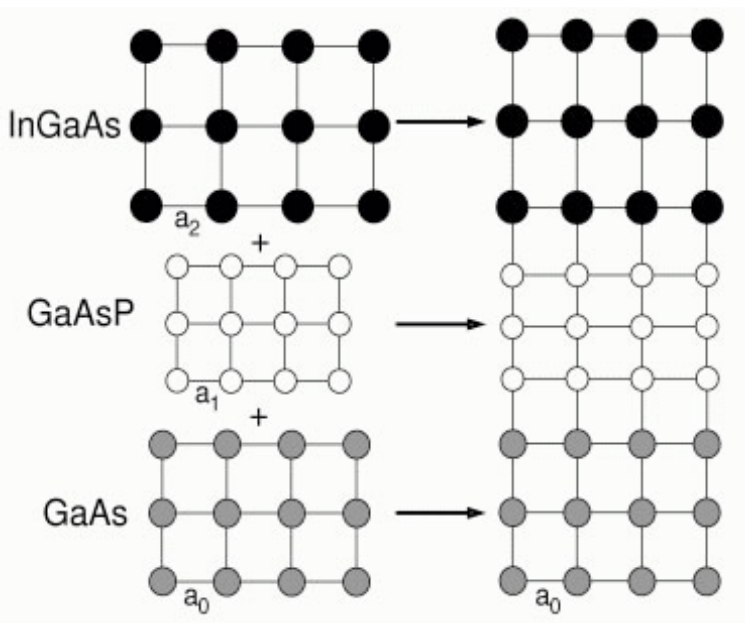

Fig. 4. Stress balancing technique incorporated in MQW structures.

Two different SB-QWSC designs will be presented here and compared to a control InGaP/GaAs tandem cell. The bottom cells of the SB-QWSC tandem cells are identical with the exception of the multi-quantum well (MQW) structure. The MQW structures in the top limited (TL) and current matched (CM) cells were grown with exciton peaks at $918 \mathrm{~nm}$ and $922 \mathrm{~nm}$ respectively. The SBQWSC bottom cells were grown at the EPSRC National Centre for III-V Technologies using Metal Organic VapourPhase Epitaxy (MOVPE) on GaAs substrates. The tunnel junctions and InGaP top cells were overgrown at Energies Nouvelles et Environment in Belgium. The final processing stage was again performed at the EPSRC National Centre in Sheffield. The tandem cell structures are depicted in Fig. 5. Table 1 shows the layer widths for the $\mathrm{i}-$ and $n-$ regions of TL and CM SB-QWSC.

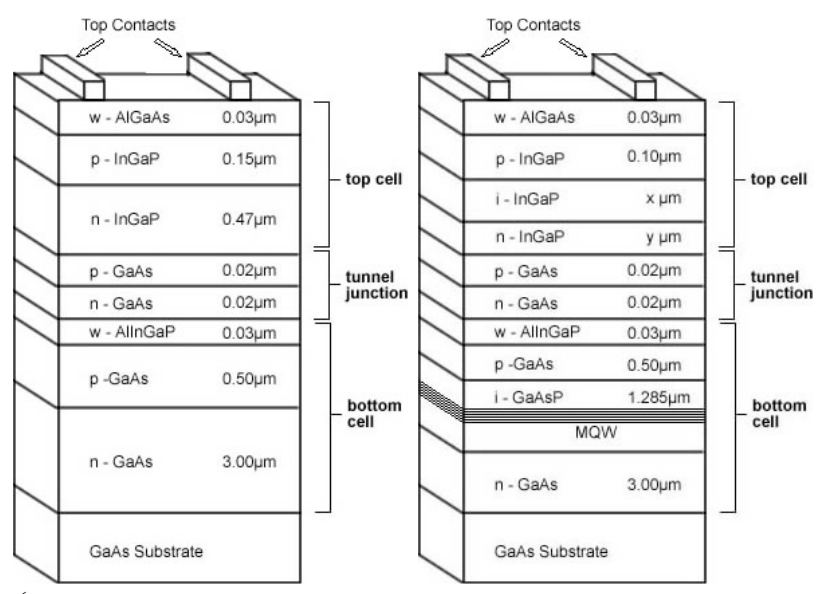

(a)

(b)

Fig. 5. (a) Control and (b) SB-QWSC tandem structures. 


\begin{tabular}{c|c|c} 
Cell & i-region width & n-region width \\
\hline & $\mathrm{x} \mu \mathrm{m}$ & $\mathrm{y} \mu \mathrm{m}$ \\
\hline $\mathrm{TL}$ & 0.13 & 0.52 \\
\hline $\mathrm{CM}$ & 0.34 & 0.57
\end{tabular}

Table 1. InGaP top cell i-region and n-region layer widths

\section{Quantum Efficiency Measurements and Modelling}

Measuring the quantum efficiency (QE) of a multijunction cell in a monolithic, series connected tandem configuration is more challenging than for single junction solar cells. The current through the tandem cell is limited by the lowest current producing junction. During characterization, the junction not being characterized will not pass any current unless illuminated. In order to overcome this, dc light-bias was applied on the junction not being characterized without affecting the junction under test. Using an infra-red LED and a blue LED, the bottom and top junctions respectively can be light biased during the measurement. The amount of light biasing is adjusted to match the maximum current output of the junction under test. Over-light biasing can forward bias the light-biased junction and in turn the junction under test becomes reversed biased since the tandem cell is held at zero volts bias by an active bias control. In this case the QE measured will not reflect the actual $Q E$ at zero volts bias. The junction under test is illuminated by a chopped light source monochromator and measured by a lock-in amplifier to minimize noise. The $\mathrm{QE}$ of the junction is obtained after comparison to a reference scan of a calibrated silicon cell with a known QE. This technique produces QE measurements accurate to within $5 \%$.

The measured QE's of the Control and CM cells are depicted in Fig.3. The exciton peak, centred at 922nm, of the SB-QWSC can be clearly seen. The presence of the SB-QWSC extends the QE of GaAs in the 900 to $925 \mathrm{~nm}$ range. This in conjunction with an improved InGaP top cell

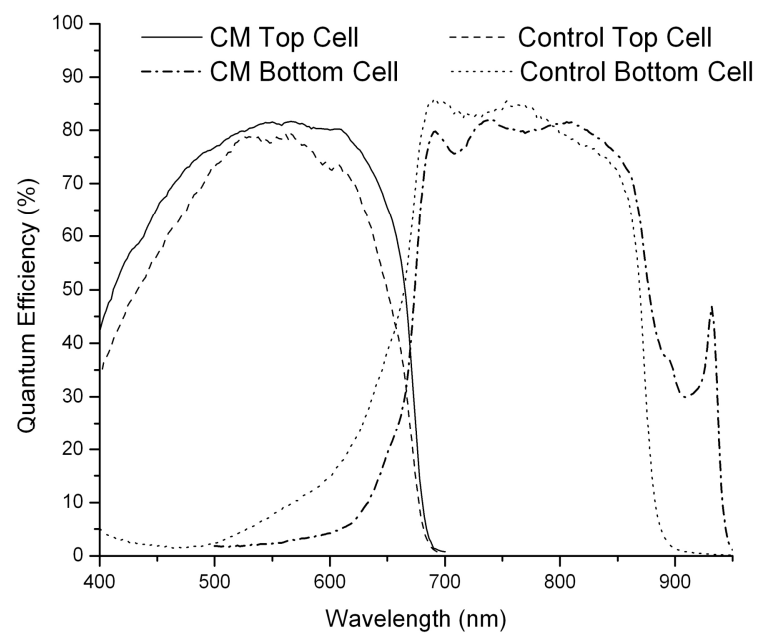

Fig. 6. Quantum efficiencies of $\mathrm{CM}$ and control tandem cells. makes the $\mathrm{CM}$ tandem cell into a current matched dualjunction cell.

The experimental QE measurements are modelled using SOL, a 1-d drift diffusion model developed at Imperial College London. Fig. 7 depicts the measured and modelled QE for the TL tandem cell. As seen the modelling accuracy is high with $1 \%$ agreement for the top cell and 5\% agreement for the SB-QWSC, both within the experimental error. The accuracy of the model enables prediction of current matched tandem cell configurations to be made by integrating the QE over a particular spectrum.

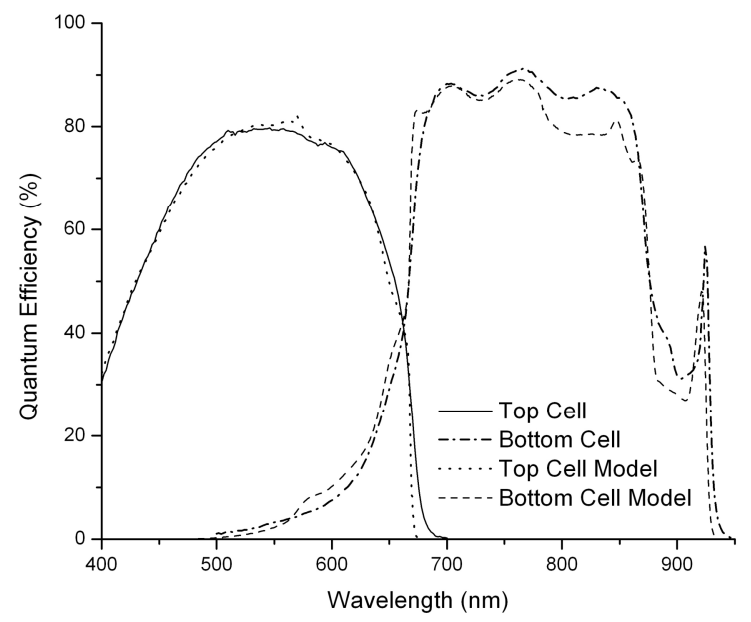

Fig. 7. The measured and modelled QE of the top cell limited tandem.

The TL tandem cell was fabricated prior to the development of the current matched $\mathrm{CM}$ tandem cell. This cell demonstrated a high quality SB-QWSC bottom junction with a projected short-circuit current density of $148.4 \mathrm{~A} / \mathrm{m}^{2}$ in Am1.5g spectrum. The choice of top cell $\mathrm{i}-$ region and $n$-region width for the current matched tandem in Table 1 were optimized based on the SOL fit to the TL tandem in Fig. 7. The CM tandem top cell and tunnel junction were then overgrown on a second SB-QWSC.

\section{LIGHT I-V EFFICIENCY MEASUREMENTS}

Monolithic multi-junction solar cells are very susceptible to spectral variations due to the fact that the spectrum determines the current limiting junction. For example a dual junction tandem cell under a blue rich spectrum will be limited by the current in the bottom cell. Therefore small variations in the spectrum can affect the total efficiency of the cell greatly. In the absence of an AM1.5g light source a different method needs to be employed to determine the I-V characteristics of a multijunction solar cell.

A $3000^{\circ} \mathrm{K}$ black body light source was utilized to perform the light I-V characterization. This method is not optimal as the output efficiency of the tandem cells would not reflect the expected output efficiency under AM1.5g spectrum, for which the tandem cells were optimized. However this method is adequate for demonstrating the principle of efficiency enhancement with a SB-QWSC. 
Another method employed was simulated AM1.5g illumination conditions using two monochromatic laser sources that illuminated each junction separately. This method demonstrated higher efficiencies; however the narrow band-width of the laser sources meant that the SBQWSC did not exhibit its full potential. Also the high experimental uncertainty in this method of determining the illumination intensity of each laser source restricted the accuracy of the efficiency estimate

\begin{tabular}{l|c|c}
\multirow{2}{*}{ Cell } & \multicolumn{2}{|c}{$\mathrm{J}_{\mathrm{sc}}, \mathrm{A} / \mathrm{m}^{2}$} \\
\cline { 2 - 3 } & Top Cell & Bottom Cell \\
\hline $\mathrm{CM}$ & 125.1 & 124.7 \\
\hline $\mathrm{TL}$ & 122.5 & 148.4 \\
\hline Control & 110.1 & 126.5
\end{tabular}

Table 2. Calculated short-circuit current densities under AM1.5g spectrum

The expected short circuit current densities of the three tandem cells were calculated using the measured QE's and the standard AM1.5g spectrum (see Table 2). In order to perform the I-V curve

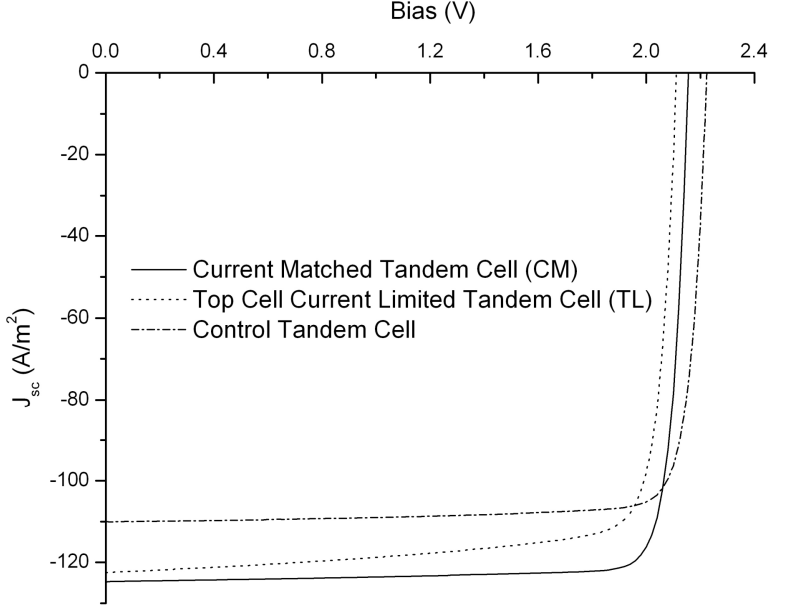

Fig. 8. Light I-V curves for the three cells under $3000^{\circ} \mathrm{K}$ black body spectrum at $1000 \mathrm{~W} / \mathrm{m}^{2}$

measurement the intensity of the $3000^{\circ} \mathrm{K}$ light source was adjusted so that the output short circuit current density of the tandem cell matched the lowest short-circuit current density from the constituent junctions. The I-V curves are shown in Fig. 8 and the cell parameters in Table 3.

\begin{tabular}{c|c|c} 
Cell & $\begin{array}{c}\text { Fill } \\
\text { Factor } \\
(\mathbf{\%})\end{array}$ & $\begin{array}{c}\text { Efficiency } \\
\mathbf{( \% )}\end{array}$ \\
\hline $\mathrm{CM}$ & 87.1 & 23.4 \\
\hline TL & 81.2 & 21.0 \\
\hline Control & 86.1 & 21.1
\end{tabular}

Table 3. Experimental tandem cell efficiencies in a $3000^{\circ} \mathrm{K}$ black-body spectrum at intensity of $1000 \mathrm{~W} / \mathrm{m}^{2}$.

As expected the TL tandem cell exhibits a poor fill factor which can be attributed to the large mismatch between the bottom and top cell current densities. The error in determining the efficiency by this method is estimated to be $3.5 \%$. Therefore the efficiency of the current matched $\mathrm{CM}$ cell under a $3000^{\circ} \mathrm{K}$ black body spectrum of total irradiance of $1000 \mathrm{~W} / \mathrm{m}^{2}$ is determined as $(23.4 \pm 0.8) \%$.

\section{CONCLUSIONS}

We have demonstrated that incorporation of a SB-QWSC in an InGaP/GaAs monolithic tandem cell increases the bottom cell photocurrent. Thus the bottom cell current limiting constraint can be lifted. Based on measurements and QE fits on a top cell limited SB-QWSC tandem a current-matched top cell has been designed using SOL our cell simulator. The corresponding current matched SBQWSC tandem has been grown and a significant increase in efficiency of $2.3 \%$ absolute demonstrated compared to a control cell in a $3000 \mathrm{~K}$ black-body spectrum. This is the first experimental observation of tandem efficiency enhancement with a quantum well cell. Further optimization of the top and bottom cell for the AM1.5d spectrum could lead to a new dual junction record tandem cell for concentrator applications.

\section{REFERENCES}

[1] M. A. Green, et al, "Solar Cell Efficiency Tables (Version 27)," Progress in Photovoltaics: Research and Applications, vol. 14, pp. 45-51, 2006.

[2] D. J. Friedman, et al, "30.2\% Efficient GalnP/GaAs Monolithic Two-Terminal Tandem Concentrator Cell," Progress in Photovoltaics: Research and Applications, vol. 3(1), pp. 47-50, 1995.

[3] N. J. Ekins-Daukes, D. B. Bushnell, J. P. Connolly, K. W. J. Barnham, M. Mazzer, J. S. Roberts, G. Hill, and R. Airey, "Strain-balanced quantum well solar cells," Physica E, vol. 14, pp. 132-135, 2002.

[4] K. W. J. Barnham et al, "Quantum Well Solar Cells," Applied Surface Science, vol. 113, 1997.

[5] T. N. D. Tibbits, I. M. Ballard, K. W. J. Barnham, N. J. Ekins-Daukes, R. Airey, G. Hill, and J. S. Roberts, "The Potential for Strain Balanced Quantum Well Solar Cells in Terrestrial Concentrator Applications," presented at WCPEC-3, Osaka, Japan, 2003.

[6] A. Freundlich and I. Serdiukova, "Multi-Quantum Well Tandem Solar Cells with Efficiencies Exceeding 30\% AM0," Proc. Of $2^{\text {nd }}$ WCPEC, Vienna, vol. 3, pp.3707-3710 1998.

[7] A. J. Ptak, D. J. Friedman, S. R. Kurtz, and K. J., "Enhanced-Depletion-Width GalnNas Solar Cells Grown by Molecular-Beam Epitaxy," presented at $31^{\text {st }}$ IEEE Photovoltaics Specialists Conference and Exhibition, Lake Buena Vista, Florida, 2005.

[8] S. Sze, Physics of Semiconductor Devices: John Wiley and Sons, 1981. 